ness, or deafness. The inadequacy of financial provisions, the unevenness of home help services, and the ever-present housing difficulties were already well known, but in the course of its inquiries the working party came vividly to realize the need for improved comprehensive medical assessment and regular periodic reassessment, for uniformity of social provisions, and for better paramedical services and improved mechanical aids. In June 1966 it submitted to the Ministry of Social Security an urgent memorandum recommending that disability pensions should be related to degree of incapacity, irrespective of the cause of disability ; the payment of supplementary allowances when needed; and equality of financial assistance, with special reference to certain classes of disabled housewives, for whom there was no provision under existing regulations.

Later the working party extended its inquiries by looking into the problem of the young chronic sick already in institutions with a view to considering the sort of residential accommodation which should be provided for those who could not remain at home. It was mainly concerned with resolving two conflicting questions: Are disabled patients' interests better served by grouping them according to physical capacity, intelligence, and social background in a purposebuilt well-equipped homely unit, which might be far from home and family ? Or are they happier in a less well equipped hospital or institution nearer home? The general opinion was that at least those patients under 35 years, with the prospect of many years of residential life before them, should be accommodated in the former type of unit.

The working party also decided that medical assessment should preferably be carried out in one hospital and coordinated by one consultant. Liaison between the three main branches of the Health Servicc was found not to be so close as it should be, and not only the patients but many of their family doctors were unaware of the services available. The working party also considered that the provision of nursing aides working under the supervision of trained nurses, or in some cases the enlistment of responsible neighbours as permanent home helps, would fulfil a real need.

The Ministry of Health Memorandum 4 gives the figures of a census carried out in April 1967 showing that 4,223 chronic sick between the age of 15 and 59 were in nonpsychiatric hospitals. Of these, 502 were under 35 , of whom 101 were in special units for young chronic sick, 74 in geriatric or chronic-sick wards, 271 in other wards, and 56 accommodated by contractual arrangements. A number of them were in temporary residence to give relief to their families. The Ministry found that most of the regional hospital boards made what was called special provision for the younger chronic sick by concentrating them into certain wards or certain hospitals, but some boards considered it more suitable to place the patient in any sort of ward which was near his home. Though the patients were adequately nursed in these units, they undoubtedly lacked enough provision for occupation, hobbies, intellectual interests, and the sort of stable personal relationship which they would have been hav-

\footnotetext{
1 Brit. med. 7., 1968, 3, 563.

- Proceedings of a Symposium on the Disabled Young Adult, ed. W. H. Bradley. National Fund for Research into Crippling Diseases, Vincent House, Vincent Square, Landon S.W.1 (2 guineas net plus 13. 10d. postage).

- At Home or in Hospital ? National Fund for Research into Crippling Diseases (5s. net).

- National Health Service: Care of Younger Chronic Sick Patients in Hoopital. Ministry of Heoith, H.M.(68) 41 .
}

ing at home. The recommendations made in the Ministry's memorandum reflect how carefully and sympathetically the other two reports ${ }^{2}$ have been studied. The Ministry gives its official blessing to purpose-built units accommodating not fewer than 25 patients, which is the smallest group for which appropriate provisions can be made, and not more than 50, since larger units tend to acquire too institutional an atmosphere. And it makes a number of recommendations that will be helpful to those charged with care of the young chronic sick. A covering letter notes that the Minister intends to call for reports on progress in about 2 years' time. If these recommendations can be carried out, the welfare of the young chronic sick should be greatly improved and the confusion at present existing alleviated if not finally resolved.

\section{Delayed Neurological Effects of Electrical Accidents}

Most people who get an electric shock recover without serious effects. Some may die either from the shock or from resulting burns or injuries. After-effects are uncommon, though some kinds have been reported quite often. For instance, for many years it has been recognized that a small number of survivors may develop neurological sequelae. ${ }^{1-4}$

These may be diverse. ${ }^{5}$ They are said to include cerebral lesions resulting in hemiplegia and aphasia ; disturbances of the basal ganglia producing Parkinsonism and choreoathetosis; and sometimes lesions of the brain stem, spinal cord, peripheral nerves, or autonomic nervous system. Such effects may follow immediately after the accident or may not appear until months later.

Several mechanisms have been suggested to explain how the electric current causes injury in the central nervous system. In $1930 \mathrm{~F}$. Panse ${ }^{6}$ suggested that the effects were due to disturbance of the blood supply to the spinal cord. Other workers, impressed by such pathological changes? as damage to blood vessels, fissuring of the cortex, haemorrhage, and in particular the formation of peculiar cavities round the blood vessels, wrote in terms of "explosive suddenness "- "almost as if the cell had been blown to pieces." They sought variously to explain these changes in terms of heating effect, electrolysis, and other factors. E. A. B. Pritchard ${ }^{9}$ calculated the magnitude of some of those factors and considered such causes to be unlikely, even in a lightning

1 Alexander, L., f. industr. Hyg., 1938, 20, 191.

2 Cambier, J. M., Manifestations Nerveuses des Electrisations Accidentelles, Thesis, 1953. University of Paris. Soeppen, S., and Panse, F., Klinische Elektropathologie, 1955.
Stuttgart.

- Silversides, J., Canad. med. Ass. F., 1964, 91, 195.

- Critchley, M., Lancet, 1934, 1, 68.

- Panse, F. (1930). Cited in Koeppen and Panse (1955).

Spitzka, E. A., and Radasch, H. E., Amer. F. med. Sci., 1912, 164, 341. - Langworthy, O. R., and Kouwenhoven, W. B., Amer. F. Hyg., 1932,
16, 625.

- Pritchard, E. A. B., Lancet, 1934, 1, 1163.

10 Farrell, D. F., and Starr, A., Neurology (Minneap.), 1968, 18, 601.

11 Marty, J., Renner, R., Guennec, J., Perruchio, P., and Boisot, J., Arch. 
stroke. His own suggestion, that injury resulting from a lightning stroke might be caused by electrostatic forces, is difficult to accept, as it supposes storage of large amounts of electric charge by the body.

Recently D. F. Farrell and A. Starr ${ }^{10}$ have collected from the literature 24 cases of delayed neurological injury with the onset after the accident ranging from "some days" to 24 months in their own case. To explain the delayed onset of the injuries they suggest that the endothelial cells of the blood vessels are damaged by the current, as may happen after irradiation, and that, "if as a result of irradiation or electrically induced protein changes, these cells die or become manifestly abnormal following mitosis there would be a potential region for thrombosis and resultant alteration in blood flow."

There is at present, as those authors concede, little substantial evidence to support this hypothesis. However, disturbances of local blood flow, which may be immediate or delayed, after an electric shock have been described. Angina electrica is a recognized sequel of electric shock. J. Marty and his colleagues ${ }^{11}$ published an account of an interesting case of thromboarteritis of the left brachial artery developing in a 28-year-old radio officer two and a half years after the accidental contact of his left elbow with a capacitor charged at about 5,000 volts, which thereby discharged through his left arm.

Thus, although neurological sequelae associated with electric shock have been reported over many years, it has not been possible to explain satisfactorily their cause or causes. The relatively few cases that occur, and their diversity, make detailed pathological and clinical studies difficult.

\section{Microscopical Sequelae of Head Injury}

It is disturbing to reflect that so valuable an organ as the human brain can, with sudden changes of acceleration, be made to resemble a quivering blancmange. Stretching and rupturing of nerve fibres are the probable results of the application of such stresses.

The importance of rotational shearing forces in the production of brain injury was emphasized in the experimental work of A. H. S. Holbourn ${ }^{12}$ and by R. H. Pudenz and C. H. Shelden. ${ }^{3}$ The latter workers studied movements of the brain in response to blows, using cinematographic pictures of monkeys fitted with transparent calvaria. The evidence suggests that blood vessels and axons were specially likely to suffer damage. S. J. Strich ${ }^{4}$ confirmed the experimentalists' work in her series of pathological findings in 20 cases of head injury surviving for up to two years. She found lesions in the white matter consisting of axonal swellings (" retraction balls") and evidence of degeneration in such pathways as the pyramidal tracts and medial lemniscus in Marchi preparations. Her findings strongly suggested that nerve fibres were damaged at the time of the accident. From a pathologist's viewpoint cases of traumatic damage to the brain can roughly be divided into those in which lacerations or haemorrhages are at once evident on naked-eye inspection and those, more difficult, in which no such lesion presents. In a number of the latter cases obvious ischaemic changes, too small to be readily visible, can be found on microscopical examination. But in others routine examination is unrewarding.

Recently D. R. Oppenheimer studied at necropsy a series of cases of head injury with no gross naked-eye changes. The patients had survived for periods varying from 12 hours to a few weeks. He pointed out that in a high proportion of these cases capillary haemorrhages and severed nerve fibres without haemorrhage could be found. In this work Oppenheimer emphasized the value of the examination of frozen sections stained for microglia. The mature microglial cells (or cerebral macrophages), the only representatives of the reticuloendothelial system truly within the central nervous tissues, are fairly inconspicuous under normal conditions when routine histological preparations are examined, but when active can readily be recognized by the use of silver impregnations. The techniques employed mostly derive from the silver carbonate method used by del Rio-Hortega, whose classical work established the separation of the mesodermal microglia from the neuroectodermal elements in the nervous system, and detailed the reactions characteristic of these cells in many types of disease process. Under stimulation such as may be provided by a small focus of cellular destruction microglia will aggregate, multiply, hypertrophy, and phagocytose debris. It is not always recognized that there are satisfactory silver-staining methods for showing these cells that are simple and easy to perform, well within the compass of any laboratory without special experience. Such is the modified Weil-Davenport method employed by Oppenheimer. Its special virtue in this context is that because of their intense argyrophilia the clusters of active microglia (indicating damage) stand out black against the pale background, and hence can readily be found under only low powers of magnification, so that accurate assessment can be readily made of the extent of destruction at various sites. In three-quarters of the cases examined microglial clusters were found, and, while in one case in which the patient survived 15 hours the cells were small, from 24 hours onwards they were large and numerous. The proliferation corresponded to the sites of white matter destruction indicated in Marchi preparations. As in other studies the corpus callosum and the upper brainstem were regions specially prone to be affected.

There can be no doubt that such silver impregnations are a most useful tool for the neuropathologist, enabling the recognition of lesions that otherwise would not be identified and allowing the determination of their distribution. A particularly useful application is in the early case of brain injury before axonal changes and tract degeneration are conspicuous. It is only by using the appropriate techniques that the problems posed by the study of such brains can be approached, and only then can we hope to profit by further understanding of the mechanical forces at work in the production of the lesions concerned. As Oppenheimer says, the demonstration of lesions other than petechial haemorrhages in cases which were clinically labelled "concussion" is of interest, for permanent damage can clearly be inflicted on the brain by apparently minor injuries, and repeated blows (as in the case of the boxer) could lead to a cumulative loss of nervous tissue.

\footnotetext{
1 Holbourn, A. H. S., Lancet, 1943, 2, 438.

2 Holbourn, A. H. S., Brit. med. Bull, 1945, 3, 147.

s Pudenz, R. H., and Shelden, C. H., F. Neurosurg., 1946, 3, 487.

- Strich, S. J., Lancet, 1961, 2, 443.

5 Oppenheimer, D. R., f. Neurol. Neurosurg. Psychiat., 1968, 31, 299.
} 